\title{
Antazoline in the treatment of cardiac arrhythmias
}

\author{
S. S. SHAH \\ M.D.
}

\author{
C. H. VAIDYA \\ M.D.
}

\author{
H. V. DoshI \\ M.D. \\ M. P. Shah Medical College and Irwin Group of Hospitals, \\ Jamnager, Gujarat State, India
}

\begin{abstract}
Summary
Antazoline was administered in sixty-five episodes of various types of cardiac arrhythmia.

A complete suppression of the ectopic beats was achieved in five out of six episodes of premature atrial systoles and in twenty-one of the twenty-four episodes of ventricular premature systoles.

Conversion to sinus rhythm was observed in seven out of ten and four out of five episodes of paroxysmal atrial and nodal tachycardia respectively.

Six out of ten episodes of ventricular tachycardia were controlled by intravenous therapy. However, the drug proved to be ineffective in cases of atrial fibrillation.
\end{abstract}

The side-effects were few and transitory, consisting of nausea, vomiting and drowsiness.

\section{Introduction}

Following the reports of Graham (1947) and Craver, Barrett \& Cameron (1951) antazoline 2(N-benzylanilinomethyl)-2-imidazoline was introduced as an antihistamine and still is in use though almost completely replaced by newer antihistamines. Dutta (1948) reported that antazoline antagonized the depressant action of acetycholine on rabbit atrium and decreased the maximum rate of electrical stimulation to which atrial muscle could respond. Furthermore, it appeared to be about twice as potent as quinidine in its ability to prolong the refractory period of the atrium.

In 1952, McKechnie first demonstrated a great reduction in the number of ventricular premature contractions in man after intravenous and oral antazoline. Brown (1962) demonstrated the effectiveness of antazoline in the prevention of ventricular fibrillation during cooling and rewarming experiments in dogs. Dreifus, Rabbino \& Watanabe (1963) reported in their study of 143 episodes of arrhythmia that antazoline was effective in the suppression of atrial and ventricular premature systoles and useful in the termination of paroxysmal atrial and ventricular tachycardia. However, the drug was found to be ineffective in atrial flutter and fibrillation. Further clinical studies by Reynolds, Baird \& Clifford (1964), Kiger (1964), Herbst (1965) and Herrmann et al. (1964) confirmed the efficacy of this agent in the treatment of various cardiac arrhythmias. Recently Srinivas \& Antani (1971) and Antani (1971) tried the drug in forty and fifty cases respectively and reported similar favourable results. The purpose of this paper is to present our experience with antazoline in the management of various types of cardiac arrhythmia.

\section{Materials and methods}

The material of this report consists of sixty-five arrhythmic episodes treated with antazoline. All the patients were admitted to the Irwin Group of Hospitals, Jamnagar. In some cases the arrhythmia was the reason for admission to hospital while in others the arrhythmia developed in hospital. Occasionally patients were counted more than once in the series because of different arrhythmias occurring during the same hospitalization. All the patients were subjected to complete clinical examination with particular reference to their cardiovascular status and the underlying disease triggering the cardiac arrhythmia. A control 12 lead electrocardiogram with a long strip of leads II and $V_{1}$ was recorded to establish the type of arrhythmia. All anti-arrhythmic drugs except maintenance doses of digitalis were omitted prior to administration of antazoline. Sup- 요 portive therapeutic measures like oxygen, vaso- N pressor drugs, bronchodilators etc. were used when ్ㅐ indicated. Before attempting conversion, anti- $\bigcirc$ coagulant therapy was instituted in cases with atrial fibrillation.

In all cases of ventricular tachycardia antazoline phosphate was administered intravenously in doses of $50 \mathrm{mg}$ at intervals of $5 \mathrm{~min}$ till termination of arrhythmia or a maximum dose of $10 \mathrm{mg} / \mathrm{kg}$ body $\mathbb{\mathbb { D }}$ weight had been administered. An ECG was taken 
before injecting each fresh dose till conversion occurred, and repeated after $12 \mathrm{hr}$ and every $24 \mathrm{hr}$ in successful cases. After the reversion of the arrhythmia an effective concentration was maintained by antazoline hydrochloride $100 \mathrm{mg}$ orally 4-hourly for 2 weeks.

In all other cases antazoline hydrochloride was administered by mouth first in doses of $100 \mathrm{mg} \mathrm{4-}$ hourly; if this regimen was not effective within $24 \mathrm{hr}$, the dose was increased to $200 \mathrm{mg}$ every $4 \mathrm{hr}$ for a further six doses and further increased to $300 \mathrm{mg}$ every $4 \mathrm{hr}$ in unsuccessful cases. Absence of response to this dosage within $24 \mathrm{hr}$ was taken as failure.

The effectiveness of antazoline was considered good when all ectopic beats were abolished or an ectopic tachycardia had been converted to sinoatrial rhythm. The results were recorded as satisfactory when $70 \%$ of the ectopic beats had been cleared and when an interrupted paroxysm had not recurred within $12 \mathrm{hr}$. After the arrhythmia had been converted, antazoline was administered in the same doses for $48 \mathrm{hr}$ and then reduced to half for another $48 \mathrm{hr}$ and then suspended.

\section{Results}

Sixty-five episodes of various cardiac arrhythmias in fifty-six patients were included in the present series. There were thirty-one males and twenty-five females, with ages ranging from 13 to 65 years, mean $40 \cdot 2$. As shown in Table 1 there were six episodes of premature atrial systoles, twenty-four episodes of premature ventricular systoles, fifteen of paroxysmal supraventricular tachycardia, ten of auricular fibrillation and ten of ventricular tachycardia. Out of fifty-six patients, fifty had organic heart disease; of these, twenty-five had rheumatic heart disease, twenty had acute myocardial infarction, four had congenital heart disease and one had thyrotoxic heart disease. Two cases developed a cardiac arrhythmia as a terminal event in uraemia with hyperkalemia and two patients developed supraventricular tachycardia postoperatively.

In six patients with atrial premature beats, complete suppression was obtained in five (Fig. 1) and ectopic contractions were reduced by $70 \%$ in the remaining one.

Of twenty-four episodes of ventricular premature beats, twenty-one were completely suppressed within $24 \mathrm{hr}$ (Fig. 2) while there was 70\% suppression in three. Following the withdrawal of antazoline there was a recurrence in only two patients, both of whom were suffering from myocardial infarction. Antazoline was re-administered and premature beats were again eliminated. All the fourteen episodes of ventricular premature beats due to digitalis responded to antazoline.

Conversion to regular sinus rhythm in the present series was achieved in seven out of ten and four out of five episodes of paroxysmal atrial and nodal tachycardia respectively (Fig. 3). One case of paroxysmal atrial tachycardia with thyrotoxic heart disease did not respond to antazoline, while there was a recurrence in one case after $48 \mathrm{hr}$ when the antazoline dosage was halved.

All the patients who had atrial fibrillation demonstrated no significant change in ventricular rate. The atrial mechanism remained unchanged and in no case was sinus rhythm restored. All these cases had atrial fibrillation of more than 3 years' duration.

Termination of paroxysmal ventricular tachycardia by intravenous administration of antazoline phosphate was fairly successful (Fig. 4). Out of ten episodes so treated there was termination of the attack in six. Two cases had advanced uraemia with hyperkalemia; though included as failures in this series they died only after four and six doses of 50 $\mathrm{mg}$ each of antazoline had been injected. Both of them developed atrial standstill; the ventricular rate

TABLE 1. Showing the results of conversion of arrhythmias with antazoline therapy

\begin{tabular}{|c|c|c|c|c|c|c|}
\hline \multirow{2}{*}{$\begin{array}{l}\text { Sr. } \\
\text { no. }\end{array}$} & \multirow{2}{*}{ Type of arrhythmia } & \multirow{2}{*}{$\begin{array}{l}\text { Total no. } \\
\text { of episodes }\end{array}$} & \multicolumn{4}{|c|}{ Response } \\
\hline & & & Good & Satisfactory & Poor & $\begin{array}{l}\% \text { of good } \\
\text { response }\end{array}$ \\
\hline 1 & Atrial ectopic beats & 6 & 5 & 1 & - & $83 \cdot 3$ \\
\hline 2 & Ventricular ectopic beats & 24 & 21 & 3 & - & $87 \cdot 5$ \\
\hline \multirow[t]{3}{*}{3} & Paroxysmal supraventricular tachycardia & 15 & 11 & 2 & 2 & $73 \cdot 3$ \\
\hline & (a) Atrial & 10 & 7 & 1 & 2 & $70 \cdot 0$ \\
\hline & (b) Nodal & 5 & 4 & 1 & - & $80 \cdot 0$ \\
\hline 4 & Atrial fibrillation & 10 & - & - & 10 & - \\
\hline 5 & Ventricular tachycardia & 10 & 6 & 1 & 3 & $60 \cdot 0$ \\
\hline
\end{tabular}




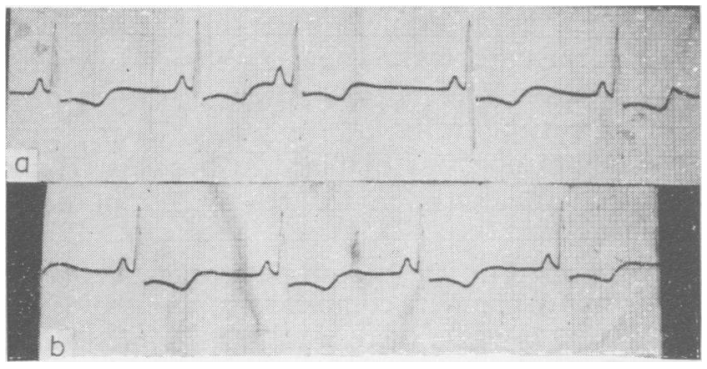

FIG. 1. ECG (lead II) of a patient with atrial extrasystoles. (a) Before and (b) after conversion with antazoline.

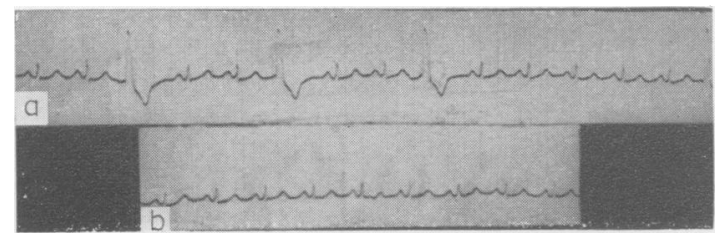

FIG. 2. ECG (lead II) of a patient with ventricular extrasystoles. (a) Before and (b) after conversion with antazoline.

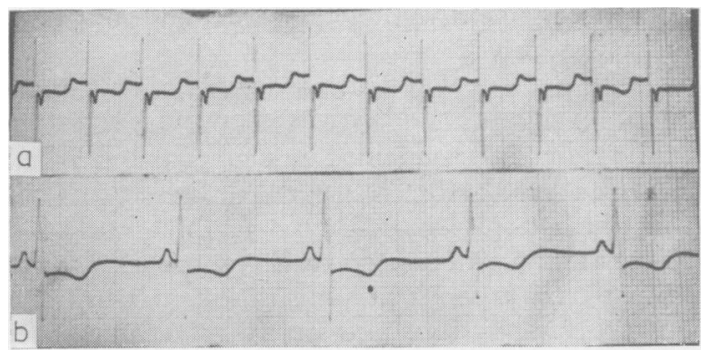

FIG. 3. ECG (lead II) of a patient with paroxysmal supraventricular tachycardia. (a) Before and (b) after conversion with antazoline.

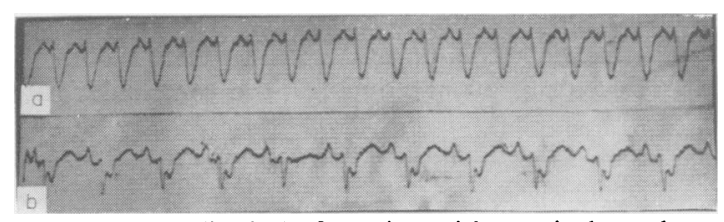

FIG. 4. ECG (lead II) of a patient with ventricular tachycardia. (a) Before and (b) after conversion with antazoline.

was reduced to less than $30 / \mathrm{min}$ and QRS complexes were widened to more than $0 \cdot 16 \mathrm{sec}$ with tall $\mathrm{T}$ waves.

The side-effects observed were nausea, vomiting and drowsiness. Nausea and vomiting were more common when the drug was taken on an empty stomach. Drowsiness was another common sideeffect particularly when the dose was more than $800 \mathrm{mg} /$ day. Of the fifty-six patients studied, ten reported these side-effects. They were not serious enough to warrant the withdrawal of the drug.

\section{Discussion}

The reported results with antazoline in the various types of cardiac arrhythmias are compared in Table 2. Only those episodes exhibiting an excellent response are included in the table for comparison. As shown in Table 1, five out of six patients having atrial premature beats and twenty-one out of twentyfour having ventricular premature beats were treated successfully in this series. Similar results were reported by various workers (Kline et al., 1962; Dreifus et al., 1963; Kiger, 1964; Herrmann et al., 1964; Srinivas \& Antani, 1971; Antani, 1971). It appears from this that antazoline is effective in controlling atrial and ventricular premature beats regardless of aetiology. Similarly, antazoline was found to be effective in paroxysmal atrial and nodal tachycardias. About $70 \%$ of episodes of supraventricular tachycardia in the present series were converted to sinus rhythm with oral antazoline. Dreifus et al. (1963) treated thirteen cases of paroxysmal atrial tachycardia with intravenous antazoline with only one failure; six patients with nodal rhythm were treated orally with two failures and five were treated intravenously with no failure. Similar good results were reported by Kiger (1964) and Herrmann et al. (1964). Recently Srinivas \& Antani (1971) ang $\overrightarrow{0}$ Antani (1971) reported conversion to sinus rhythro N in more than $80 \%$ of their cases of paroxysma supraventricular tachycardia with intravenous antazoline and found the drug to be superior to quinidine and procainamide.

There are conflicting reports of the effectiveness of antazoline in auricular fibrillation and flutter. Leon-Sotomayor (1963), Dreifus et al. (1964) and Herbst (1965) reported that antazoline was not useful in the conversion of atrial fibrillation and flutter. Kline et al. (1962) obtained conversion to sinus rhythm in one of their three cases. Our ten patients with atrial fibrillation did not respond to antazoline. In contrast to this Kiger (1964), Herrmann et al. (1964), Srinivas \& Antani (1971) and Antani (1971) reported conversion to sinus rhythm in more than $50 \%$ of their cases of atrial fibrillation and flutter. Probably these differences are due to differences in the mode of administration of drug and to chronicity of the arrhythmia.

Kline et al. (1962) have reported successful con- 요 version to sinus rhythm in two out of four cases of $N$ ventricular tachycardia. Our experience was also encouraging, with conversion in six out of ten cases. The observations of Dreifus et al. (1963), Herrmann et al. (1964) and Antani (1971) were similar.

The mechanism of the anti-arrhythmic action of antazoline is presumably its interference with membrane permeability to potassium and sodium resulting in decreased conduction velocity between fibres. In addition it antagonizes the depressant 
TABLE 2. Showing comparative results with antazoline in various types of cardiac arrhythmias

\begin{tabular}{|c|c|c|c|c|c|c|c|c|}
\hline $\begin{array}{l}\text { Sr. } \\
\text { no. }\end{array}$ & Type of arrhythmia & $\begin{array}{c}\text { Kline } \\
\text { et al. } \\
(1962)\end{array}$ & $\begin{array}{l}\text { Dreifus } \\
\text { et al. } \\
\text { (1963) }\end{array}$ & $\begin{array}{l}\text { Kiger } \\
(1964)\end{array}$ & $\begin{array}{l}\text { Herrmann } \\
\text { et al. } \\
(1964)\end{array}$ & $\begin{array}{c}\text { Srinivas \& } \\
\text { Antani } \\
\text { (1971) }\end{array}$ & $\begin{array}{l}\text { Antani } \\
(1971)\end{array}$ & $\begin{array}{c}\text { Present } \\
\text { series }\end{array}$ \\
\hline 1 & Atrial ectopic beats $(\%)$ & 100 & 100 & 100 & $66 \cdot 7$ & 80 & 100 & $83 \cdot 3$ \\
\hline 2 & Ventricular ectopic beats $(\%)$ & 82 & $88 \cdot 7$ & 100 & $80 \cdot 6$ & 86 & $84 \cdot 6$ & $87 \cdot 5$ \\
\hline 3 & $\begin{array}{l}\text { Paroxysmal supraventricular } \\
\text { tachycardia }(\%)\end{array}$ & 100 & $92 \cdot 2$ & $86 \cdot 6$ & $70 \cdot 6$ & 83 & $89 \cdot 2$ & $73 \cdot 3$ \\
\hline 4 & Atrial fibrillation $(\%)$ & $33 \cdot 3$ & $5 \cdot 6$ & 75 & $73 \cdot 8$ & 62 & $57 \cdot 1$ & $00 \cdot 0$ \\
\hline 5 & Ventricular tachycardia $(\%)$ & 50 & 60 & 100 & 50 & - & 80 & 60 \\
\hline
\end{tabular}

action of acetylcholine (Dutta, 1948) and has a mild adrenergic-blocking action (Dreifus et al. 1964). Antazoline increased peripheral vascular resistance and decreased both stroke volume and cardiac output. These two latter properties are useful for the maintenance of mean blood pressure.

\section{Acknowledgments}

We are thankful to The Dean, M. P. Shah Medical College, Jamnagar, for allowing us to publish this paper. We are also thankful to Mr R. M. Pandya, college photographer, for his help.

\section{References}

ANTANI, J.A. (1971) A clinical evaluation of antazoline in cardiac arrhythmia. Indian Heart Journal, 23, 212.

Brown, L.W. JR (1962) Surgery of the Chest (Ed. by J. Gibbon). W. B. Saunders, Philadelphia.

Craver, B.N., Barrett, W.E. \& Cameron, A. (1951) Some pharmacological properties of 2-(phenylbenzylaminomethyl) imidazoline hydrochloride (Antistine), an antihistamine. Annals of Allergy, 9, 34.

Dreifus, L.S., McGarry, T.F., Watanabe, Y., Kline, S.R., Waldman, M. \& Likoff, W. (1963) Clinical and physiological effects of antazoline, a new antiarrhythmic agent. American Heart Journal, 65, 607.

Dreifus, L.S., Rabbino, M.D. \& Watanabe, Y. (1964) Newer agents in the treatment of cardiac arrhythmias. Medical Clinics of North America, 48, 371.
DutTA, N.K. (1948) The action of substances which an tagonize acetylcholine on the body temperature of mice before and after adrenalectomy. British Journal of Pharmacology, 3, 246.

GrahAM, J.D.P. (1947) A comparison of some antihistamine substances. Journal of Pharmacology and Experimental Therapeutics, 91, 103.

Herbst, R. (1965) Bad Orb, Germany Zur Behandlung paroxysmaler Herzrhythmusstorungen. Medical Klinic, 60, 27.

Herrmann, G.R., Secrest, C.R., Vilbig, G.J., Quint, R.A. \& Herrmann, A.W. (1964) Antiarrhythmic and Antifibrillary Antazoline: A Clinical Study. Journal of the Louisiana State Medical Society, 116, 145.

KIGER, R.G. (1964) An evaluation of antazoline as an antiarrhythmic agent. Journal of the South Carolina Medical Association, 60, 41.

Kline, S.R., Dreifus, L.S., Watanabe, Y., McGarry, T.F. \& LikofF, W. (1962) Evaluation of the antiarrhythmic properties of antazoline-A preliminary study. American Journal of Cardiology, 9, 564.

LEON-Sotomayor, L. (1963) A clinical evaluation of antiarrhythmic properties of antazoline. American Journal of Cardiology, 11, 646.

MCKeChNiE, J.K. (1952) The cardiac action of the antihistamine compounds. A review of the literature and a preliminary case report. South African Medical Journal, 26, 609.

Reynolds, E.W., Baird, W.M. \& Clifford, M.E. (1964) A clinical trial of antazoline in treatment of arrhythmias. American Journal of Cardiology, 14, 513.

Srinivas, H.V. \& ANTANi, J.A. (1971) Experience in conversion of cardiac arrhythmia with antazoline (Antistine). Journal of Association of Physicians of India, 19, 363. 